\title{
Online mass spectrometric aerosol measurements during the MINOS campaign (Crete, August 2001)
}

\author{
J. Schneider ${ }^{1,2}$, S. Borrmann ${ }^{2,1}$, A. G. Wollny ${ }^{3,4}$, M. Bläsner ${ }^{3,5}$, N. Mihalopoulos ${ }^{6}$, K. Oikonomou ${ }^{6,7}$, J. Sciare ${ }^{7}$, \\ A. Teller ${ }^{8}$, Z. Levin ${ }^{8}$, and D. R. Worsnop ${ }^{9}$ \\ ${ }^{1}$ Cloud Physics and Chemistry Dept., Max Planck Institute for Chemistry, Mainz, Germany \\ ${ }^{2}$ Institute for Atmospheric Physics, Johannes Gutenberg University, Mainz, Germany \\ ${ }^{3}$ ICG-1, Research Center Jülich, Germany \\ ${ }^{4}$ now at: Aeronomy Laboratory, National Oceanic and Atmospheric Administration, Boulder, Colorado, USA \\ ${ }^{5}$ now at: Hochschule Niederrhein, Mönchengladbach, Germany \\ ${ }^{6}$ University of Crete, Heraklion, Crete \\ ${ }^{7}$ LSCE, Bat 709, CEA Orme des Merisiers, Gif/Yvette, France \\ ${ }^{8}$ Department of Geophysics and Planetary Sciences, Tel Aviv University, Tel Aviv, Israel \\ ${ }^{9}$ Aerodyne Research Inc., Billerica, MA, USA
}

Received: 10 June 2003 - Published in Atmos. Chem. Phys. Discuss.: 25 July 2003

Revised: 18 December 2003 - Accepted: 19 January 2004 - Published: 23 January 2004

\begin{abstract}
Mass spectrometric analysis of volatile and semivolatile (=non-refractory) aerosol particles have been performed during a field study in the summer Eastern Mediterranean. A size-resolved, quantitative mass spectrometric technique (the Aerodyne Aerosol Mass Spectrometer, AMS) has been used, and the results are compared to filter sampling methods and particle sizing techniques. The different techniques agree with the finding that the fine particle mode $(D<1.2 \mu \mathrm{m})$ consisted mostly of ammonium sulfate and of organic material. The aerosol sulfate ranged between 2 and $12 \mu \mathrm{g} / \mathrm{m}^{3}$. On most days, ammonium was closely correlated with sulfate, suggesting ammonium sulfate as the major aerosol component, but on days with high sulfate mass concentrations, the sulfate was not fully neutralized by ammonium. Trajectories indicate that the aerosol and/or its precursors originate from South-Eastern Europe. The source of the ammonium sulfate aerosol is most likely fossil fuel burning, whereas the organic aerosol may also originate from biomass burning. Ion series analysis of the organics fraction in the mass spectrometer indicated that the major component of the organics were oxygenated organics which are a marker for aged, photochemically processed aerosol or biomass burning aerosol. The non-refractory aerosol compounds, measured with the Aerosol Mass Spectrometer, contributed between 37 and 50\% to the total aerosol mass in the fine mode. A second mass spectrometer for single particle analysis by laser ablation has been used for the first time in the field during this study and yielded results, which agree with filter samples of
\end{abstract}

Correspondence to: J. Schneider

(schneider@mpch-mainz.mpg.de) the coarse particle mode. This mode consisted of sea salt particles and dust aerosol.

\section{Introduction}

The Mediterranean is a region with very high solar intensity during the summer months, leading to high photochemical activity. Together with the influence of polluted air from $\mathrm{Eu}-$ rope, this leads to high ozone concentrations over the eastern Mediterranean in summer (Lelieveld et al., 2002; Kouvrakis et al., 2000). Aerosol particles can play an important role in this context, since they can reduce the surface radiation by scattering the incoming solar radiation back to space. It has been proposed by Lelieveld et al. (2002), that these anthropogenic aerosols might have an effect on the sea surface temperature, followed by a decrease of precipitation in northern Africa.

Several studies investigated origin and effect of aerosol in the Mediterranean. For example, Markowicz et al. (2002) found that the Mediterranean aerosol reduces the sunlight intensity at the ground by $17.9 \mathrm{Wm}^{-2}$. Sciare et al. (2003a), who performed a one-month study in summer 2000 on Crete, identified Central Europe as the major source for black carbon (BC) and non-sea-salt sulfate (nss-SO ${ }_{4}$ ) over the Eastern Mediterranean. Ganor et al. (2000), who investigated anomalously high sulfate levels in the Eastern Mediterranean, concluded that sulfate production by DMS (Dimethylsulfide) oxidation contributed to no more than $21 \%$ to the nss$\mathrm{SO}_{4}$. Similar results have been found by Mihalopoulos et al. (1997) and Kouvrakis and Mihalopoulos (2002) who 
found that the biogenic contribution to the nss- $\mathrm{SO}_{4}$ ranges between $1 \%$ and $23 \%$, dependent on season.

Since the optical properties of aerosol particles are dependent on their size and composition, a size-resolved chemical analysis is necessary to understand the radiative influence of aerosol particles further. Also, chemical composition of the aerosol particles can give information about origin and formation processes of the aerosol. Furthermore, the chemical composition of the aerosol particles influences cloud formation mechanisms.

Quantitative mass spectrometric measurement of various aerosol compounds can be achieved by separated evaporation and ionization with subsequent mass spectrometric analysis of the molecular ions (Jayne et al., 2000). Complementary to this technique, single particle analysis is needed because the mixture state (internal/external) of the aerosol also influences the optical properties (Noble and Prather, 2000). However, the most frequently used single particle analysis method is laser ablation, which is limited in the ability of quantitative determination of the composition within individual ambient aerosol particles (e.g. Gross et al., 2000). Furthermore, the optical detection of the single particles limits the detection range on the lower side at about $100 \mathrm{~nm}$, dependent on the instrument type.

Here we report on mass spectrometric aerosol measurements performed during the Mediterranean Intensive Oxidant Study (MINOS) in August 2001 at Crete. This campaign was dedicated to investigate the anthropogenic contributions to the environmental conditions observed over the summer Eastern Mediterranean (Lelieveld et al., 2002). This paper focuses on the chemical composition of the aerosol particles inferred from two mass spectrometric techniques as well as from filter sampling methods. These measurements were accompanied by various other techniques to determine size and number density of the aerosol.

\section{Experimental}

The measurements have been carried out during the MINOS project at Finokalia, Crete, Greece. This meteorological station of the University of Crete is located on a hilltop at $35^{\circ} 24^{\prime} \mathrm{N}, 25^{\circ} 60^{\prime} \mathrm{E}$, at $150 \mathrm{~m}$ above sea level, on the northern coast of Crete (Mihalopoulos et al., 1997). The data collection period of the MINOS campaign lasted from 1 August 2001 until 24 August 2001.

At the meteorological station, the size distribution of aerosol particles with diameters below $200 \mathrm{~nm}$ was measured with a TSI 3040 diffusion particle sizer, which includes a TSI 3025 condensation particle counter. Chemical analysis of aerosol particles was performed using a MOUDI (micro orifice uniform deposition impactor) and quartz filter samples with subsequent ion chromatographic analysis. Details of the MOUDI and filter samples can be found in Sciare et al. (2003b).
In a measurement container on a site $30 \mathrm{~m}$ below the meteorological station with a horizontal distance of about $300 \mathrm{~m}$, the following instruments operated by the Cloud Physics and Chemistry Deptartment of the Max Planck Institute for Chemistry and by the Research Center Jülich were located: Two optical particle counters (PCS 2000 and PCS 2010, Palas Inc.) to measure the size distribution of particles with diameters larger than $270 \mathrm{~nm}$ (PCS 2010) and $330 \mathrm{~nm}$ (PCS 2000), a TSI 3025 particle counter to measure the number density of aerosol particles with $D>3 \mathrm{~nm}$, as well as two online mass spectrometers for the chemical analysis of the aerosol ensemble and of single particles: The Aerodyne Aerosol Mass Spectrometer (AMS) and the Single Particle Laser Ablation Time-of-flight Mass Spectrometer (SPLAT), both of which will be described below.

The container, which was upwind of the hill during the whole measurement period, had two vertical particle inlets made out of stainless steel with a diameter of $63 \mathrm{~mm}$ each, $2 \mathrm{~m}$ above the container roof. Ambient air was pumped through these tubes with a flow of $10 \mathrm{~m}^{3} / \mathrm{h}$ for each inlet. The sample tubes for the aerosol instruments were designed to be near-isokinetic. The tubings to the optical particle counters were made without bends, while it was necessary to include one $90^{\circ}$-bend before the particles were transmitted into the SPLAT inlet system. The wall losses in a $90^{\circ}$-bend can be estimated according to Hinds (1999) as the product of the particle Stokes number and the bend angle $(\pi / 2)$ and are smaller than $10 \%$ for particles with diameters up to $10 \mu \mathrm{m}$ at the chosen air flow of $10 \mathrm{~m}^{3} / \mathrm{h}$. The inlet flow to the AMS was separated from the $63 \mathrm{~mm}$ tube through a stainless steel tube with an inner diameter of $0.15 \mathrm{~cm}$ and a length of $1 \mathrm{~m}$. The AMS measured sample rate was nominally $1.4 \mathrm{~cm}^{3} / \mathrm{s}$, corresponding to a residence time inside the $0.15 \mathrm{~cm}$ tube of $1.3 \mathrm{~s}$. Particle losses were calculated for diffusive, settling, and inertial losses using the formulas given by Hinds (1999). These losses inside the $0.15 \mathrm{~cm}$ tube amount to $7 \%$ for $50 \mathrm{~nm}$ particles and decrease to $0.6 \%$ for $1.5 \mu \mathrm{m}$ particles, a size that represents the upper limit of the AMS inlet transmission.

\subsection{The aerosol mass spectrometer (AMS)}

\subsubsection{General description}

Online particle analysis has been carried out starting $16 \mathrm{Au}-$ gust with the Aerodyne Aerosol Mass Spectrometer (AMS). The instrument has been described in detail previously (Jayne at al., 2000; Allan et al., 2003a; Jimenez et al., 2003a), so it will be only briefly reviewed here: Aerosol particles with vacuum aerodynamic diameters between 50 and $1500 \mathrm{~nm}$ are focused onto a narrow beam by means of an aerodynamic lens and are separated from the gas by differential pumping. The lens transmission is approximately $100 \%$ for particles with size diameters between 80 and $600 \mathrm{~nm}$ (see Fig. 9). After a flight distance inside the vacuum chamber of $390 \mathrm{~mm}$, the particles are flash-vaporized on a hot 
surface (approx. $500-700^{\circ} \mathrm{C}$ ). This procedure evaporates the volatile and semi-volatile compounds of the aerosol. The remaining, non-volatile fraction is usually called "refractory", so it has become common to refer to the vaporized part as "non-refractory" aerosol fraction (Drewnick et al., 2003). The molecules are ionized by electron impact at an energy of $70 \mathrm{eV}$ and analyzed by a quadrupole mass spectrometer (Balzers QMA 410, rod length $30 \mathrm{~cm}$, rod diameter: $16 \mathrm{~mm}$ ). Since the evaporation and ionization processes are separated and linear, the instrument can be calibrated and used for quantitative detection of aerosol components like sulfate, nitrate, ammonium etc. The instrument can be operated in two modes: (1) the mass spectrum mode: The particle beam is constantly analyzed and the whole mass range of the spectrometer is scanned with a repetition rate of $3 \mathrm{~Hz}$. This mode is used for total chemical composition measurement. (2) the time-of-flight mode: The particle beam is chopped at ca. $100 \mathrm{~Hz}$ by a rotating wheel with two slits, and the mass spectrometer is set onto specific masses, e.g. $30\left(\mathrm{NO}^{+}\right)$and 46 $\left(\mathrm{NO}_{2}^{+}\right)$for nitrate. By triggering the MS with the opening of the chopper, the size selective mass loading of the individual species can be measured. The chopper mechanism is also used for complete blocking of the beam to determine the gas-phase background. Both modes of operation were used during the MINOS campaign, alternating every $20 \mathrm{~s}$.

\subsubsection{Derivation of mass concentrations}

In order to infer quantitatively the mass concentrations of the individual aerosol compounds, the AMS needs to be calibrated in the laboratory. For this purpose, ammonium nitrate has shown to be well-suited. A test aerosol of known size and number concentration is produced by means of an atomizer, an electrostatic classifier and a particle counter. This test aerosol is introduced into the AMS and the measured ion current of the detected particles is converted to the ionization efficiency (IE) in ions per molecule. This quantity is typically in the order of $10^{-6}$ ions/molecule for nitrate. Having done so, one can convert the measured ion current into a mass concentration $C_{S}$ by the following equation:

$C_{S}=R_{S} \frac{1}{I E_{\mathrm{NO}_{3}}} \frac{M W_{\mathrm{NO}_{3}}}{N_{A} Q} \sum I_{f}$,

where $\sum I_{f}$ is the sum of the ion current of the fragment ions originating from the parent ion, $I E_{\mathrm{NO}_{3}}$ is the ionization efficiency of nitrate inferred from the calibration procedure, $\mathrm{Q}$ is the volumetric sample flow into the AMS, $M W_{\mathrm{NO}_{3}}$ is the molecular weight of $\mathrm{NO}_{3}, N_{A}$ is Avogadro's number and $R_{S}$ is the inverse of the relative ionization efficiency per unit mass of the species compared to the measured $I E_{\mathrm{NO}_{3}} / M W_{\mathrm{NO}_{3}}$ (Allan et al., 2003a, b; Alfarra et al., 2003). If the mass concentrations of the individual species are calculated without the relative ionization efficiency correction $R_{S}$, we refer to "nitrate equivalent" mass concentrations. Since the ionization efficiency of nitrate is determined only from
Table 1. Relative ionization efficiencies and collection efficiencies applied in the AMS data evaluation in this work.

\begin{tabular}{ccc}
\hline Species & Relative IE & $\begin{array}{c}\text { collection } \\
\text { efficiency }\end{array}$ \\
\hline Nitrate & 1.1 & 0.5 \\
Ammonium & 3.5 & 0.5 \\
Sulfate & 1.15 & 0.5 \\
Organics & 0.71 & 1 \\
\hline
\end{tabular}

the fragments $m / z=30$ and 46 (which make up $90 \%$ of the total ions produced from nitrate), the relative ionization efficiency used to infer the nitrate mass concentration is 1.1 .

An additional correction has to be applied due to the decreasing collection efficiency of non-spherical particles. It has been found that crystalline particles are less well focused as spherical PSL particles by the aerodynamic lens. We used a collection efficiency of one for organics and 0.5 for the other species. This assumes that the liquid, spherical organic aerosol is externally mixed with the internal mixture of ammonium sulfate and ammonium nitrate aerosol. The reason for this assumption and possible errors induced by it will be discussed in Sect. 3.4. The correction factors applied in this work are summed up in Table 1.

The ionization by electron impact leads to significant fragmentation of the molecules. In order to infer the fragmentation patterns of the individual species, laboratory measurements have been carried out by various users of the AMS. The fragmentation pattern of sulfate and nitrate are described in Hogrefe et al. (2003). These patterns are applied to the peaks of mass spectra measured during field studies to account for the various interferences of different species. This procedure is described in detail by Allan et al. (2003b). As an example, a mass spectrum averaged over the whole MINOS measurement period is shown in Fig. 1. We illustrate the concept using the peak at $m / z=18$ : It is composed of ionic signals from air, water, sulfate and organic molecules. The contribution of air molecules is inferred from the isotopic ratio of oxygen $\left({ }^{18} \mathrm{O}^{+}\right)$, the sulfate contribution is inferred from the laboratory fragmentation pattern (intensities of $m / z=48$ and $m / z=64$ multiplied by 0.67 ), and so is the organic contribution (equal to the organic contribution to $m / z=44$, which in turn has to be separated from the gas phase $\mathrm{CO}_{2}$ contribution to that peak.) The rest of the intensity of $m / z=18$ is attributed to water. In the mass spectrum displayed in Fig. 1, the signals from air molecules have been excluded for clarity. Similarly, the isotopic ratios of sulfur leads to the small sulfate peaks at $m / z=50$ and $66(4.62 \%$ of the sulfate contribution at $m / z=48$ and 64 , respectively). 


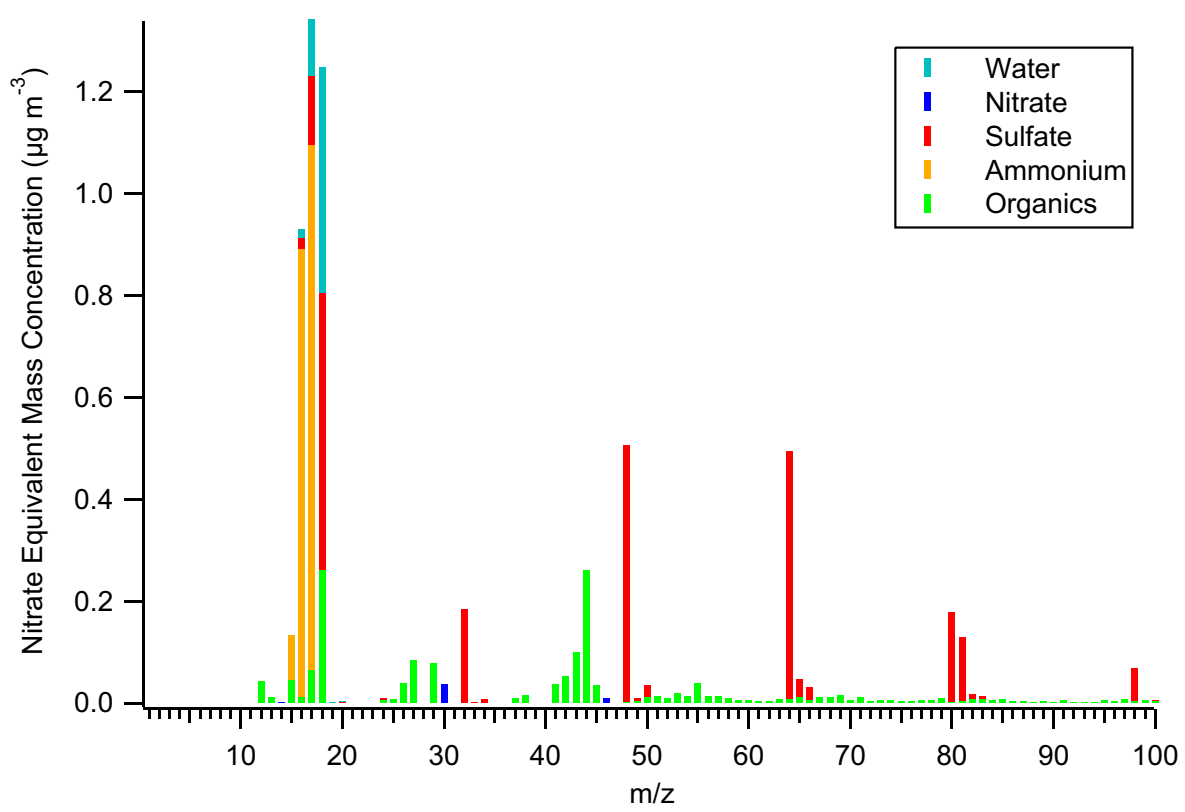

Fig. 1. Aerosol spectrum measured with the AMS, averaged over the whole sampling time span (17-23 August 2001). The contributions of the individual compounds to the peak heights are denoted by the colors. The peaks are scaled to the nitrate equivalent concentration. For details see text.

2.2 The single particle laser ablation time-of-flight mass spectrometer (SPLAT)

The SPLAT instrument was developed by Bläsner (2002) and Wollny (2002) for aircraft-based bipolar analysis of single particle composition of particles with diameters larger than $200 \mathrm{~nm}$. The design follows the proposal of Marijnissen et al. (1988) and implements both aerodynamic sizing (Prather et al., 1994) and simultaneous bipolar analysis of a single particle (Hinz et al., 1996).

The particles are transferred through a capillary $(250 \mu \mathrm{m}$ inner diameter) and a differentially pumped system into the vacuum chamber. The formed particle beam crosses two Nd:YAG laser beams both with wavelength $532 \mathrm{~nm}$. The scattered light is detected by two photo multiplier tubes. The measured velocity depends on the aerodynamic diameter (continuum conditions inside the capillary) and is used to trigger a pulsed ArF excimer laser with a wavelength of $193 \mathrm{~nm}$. The emitted UV-pulse hits the particle, ablates it and ionizes the fragments in the ion source region of a bipolar linear time-of-flight mass spectrometer (TOF-MS). Negative and positive ions are separated and mass selected in the TOF-MS.

\section{Results and discussion}

Figure 1 gives an average mass spectrum measured with the AMS, averaged over the whole sampling time span (17 August 2001-23 August 2001). The peaks are scaled to "ni- trate equivalent mass", as explained in section 2.1.2. The contributions of the individual compounds to the peaks are denoted by the color scheme. This average spectrum clearly shows that ammonium $(m / z=15,16,17)$ and sulfate signals $(m / z=32,48,64,80,81,96)$ are dominating. Fragments of sulfate ions also contribute to $m / z=16,17$, and 18. Signals from various organic fragments (e.g. $m / z=27,29,43,44$ ) are also present, but to a much lesser degree, while nitrate $(m / z=30,46)$ is almost negligible. Water signals are detected, too $(m / z=17,18)$, but can not be quantified at the present state of AMS instrumental characterization.

\subsection{Time series measurements}

Figure 2 shows the number density of aerosol particles with diameter larger than $3 \mathrm{~nm}$ for the whole MINOS time period (1 August 2001-23 August 2001). The plot includes two data sets, both of which were obtained with a TSI condensation particle counter model 3025 , one sampled air at the container site of MPI/FZJ, the other was operated at the meteorological station on the hilltop. Most of the time both data sets agree well, with the exception of an episode between 20 and 22 August, when the hilltop CPC detected markedly less particles than the container CPC. The reason for this discrepancy is most likely instrumental (e.g. water contamination of the working fluid of the CPC), since the comparison between AMS and MOUDI days yielded good agreement for these days (see Fig. 11). Generally the good agreement between the two CPCs indicates that the horizontal and vertical distance between the two stations $(\approx 300$ and $\approx 30 \mathrm{~m}$, 


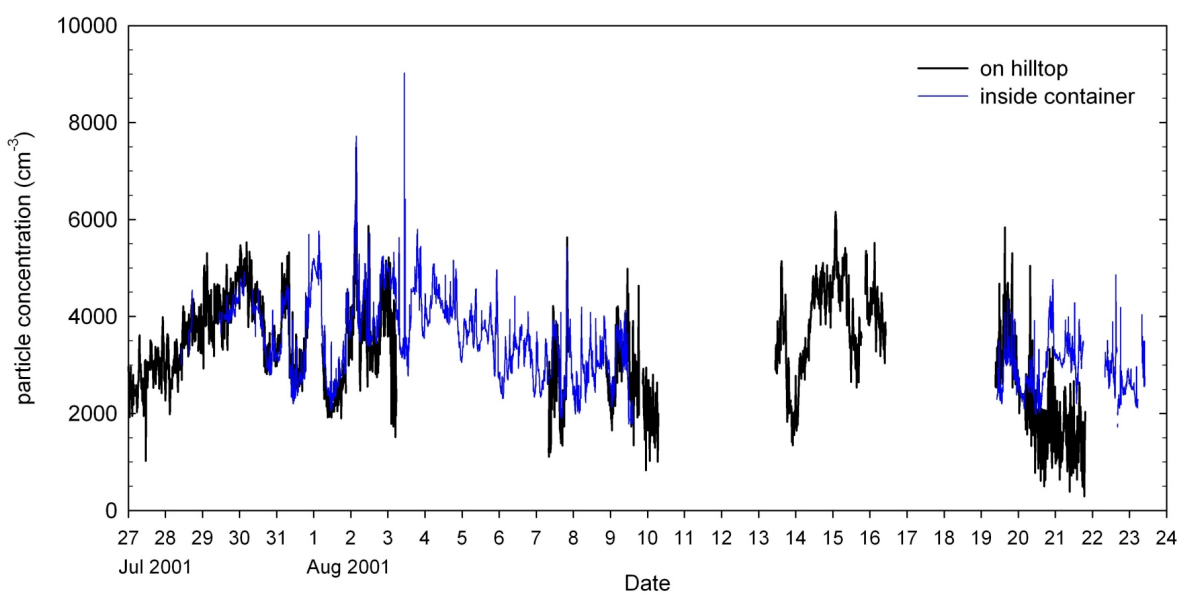

Fig. 2. Total particle number density $(D>3 \mathrm{~nm})$ measured with two TSI 3025 condensation particle counters, one inside the MPI/FZJ container, the other (as part of the diffusion particle sizer) at the station at the hilltop. The particle concentration levels range between 2000 and 6000 particles $/ \mathrm{cm}^{3}$, which is very high for a remote region.

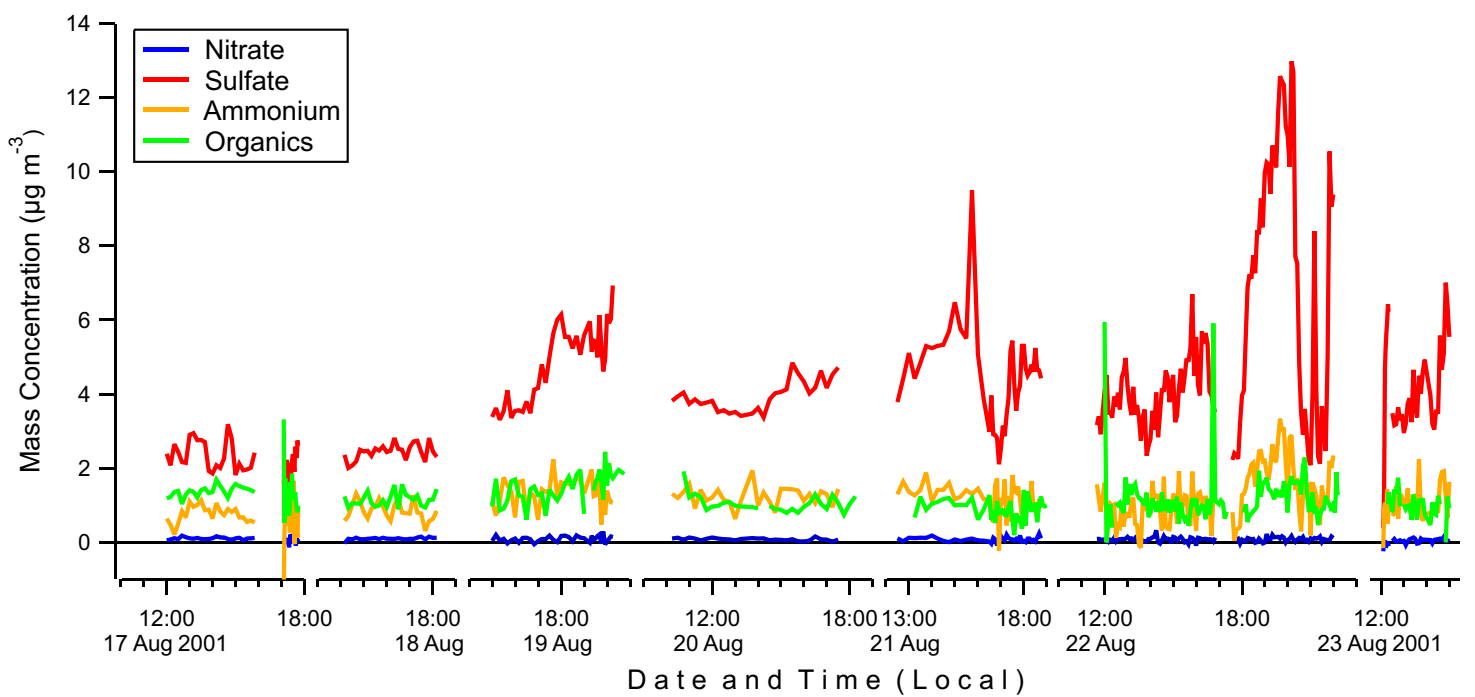

Fig. 3. Time series of the aerosol mass loading of sulfate, nitrate, ammonium, and organics, measured with the aerosol mass spectrometer (AMS). Note that the time axis has gaps during the nights, since the instrument was only operative during daytime.

respectively) were small enough to ensure that both stations sample in the same air mass.

The AMS was operational between 17 August and $23 \mathrm{Au}-$ gust 2001. Figure 3 gives the time series of the mass concentrations of sulfate, nitrate, ammonium and the total "organics" fraction. Here the "organics" fraction is defined as all signals that can not be attributed to the known inorganic substances like sulfate, nitrate, water, ammonium, and chloride. The most abundant aerosol component is sulfate, followed by ammonium and organics. The nitrate content is very low. This finding is most likely due to the high acidification of the aerosol, which means that all ammonium is neutralized by sulfate and no ammonium nitrate can be formed. Further- more, the high temperatures between 22 and $31^{\circ} \mathrm{C}$ do also prevent the formation of ammonium nitrate. The largest variations can be observed in the sulfate concentrations. The values range between 2 and $12 \mu \mathrm{g} / \mathrm{m}^{3}$, with smallest values on 17 August and 18 August 2001. These sulfate values represent non-sea-salt sulfate, since the AMS does not collect the coarse mode particles $(D>2 \mu \mathrm{m})$ which contain by far most of the sea salt mass. The contribution of sea salt particles to the fine mode $(D<2 \mu \mathrm{m})$ was found to be only $1 \%$ (Lelieveld et al., 2002).

The correlation of sulfate and ammonium is investigated more closely in Fig. 5. The dashed line represents the ratio of ammonium and sulfate for pure $\left(\mathrm{NH}_{4}\right)_{2} \mathrm{SO}_{4}$. On days 


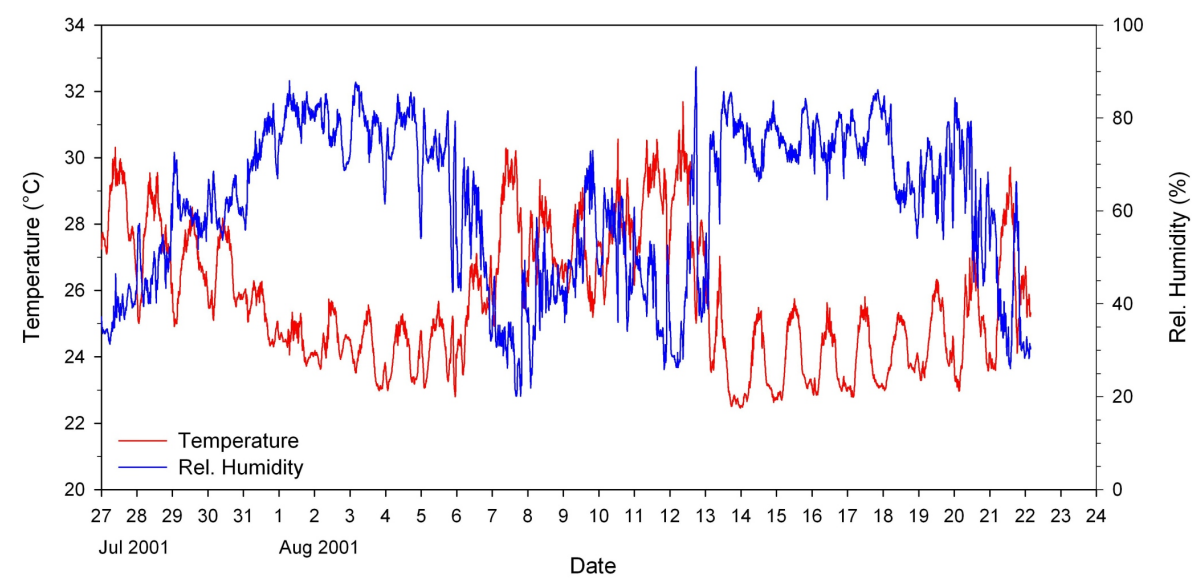

Fig. 4. Time series of temperature and relative humidity for the MINOS time period.
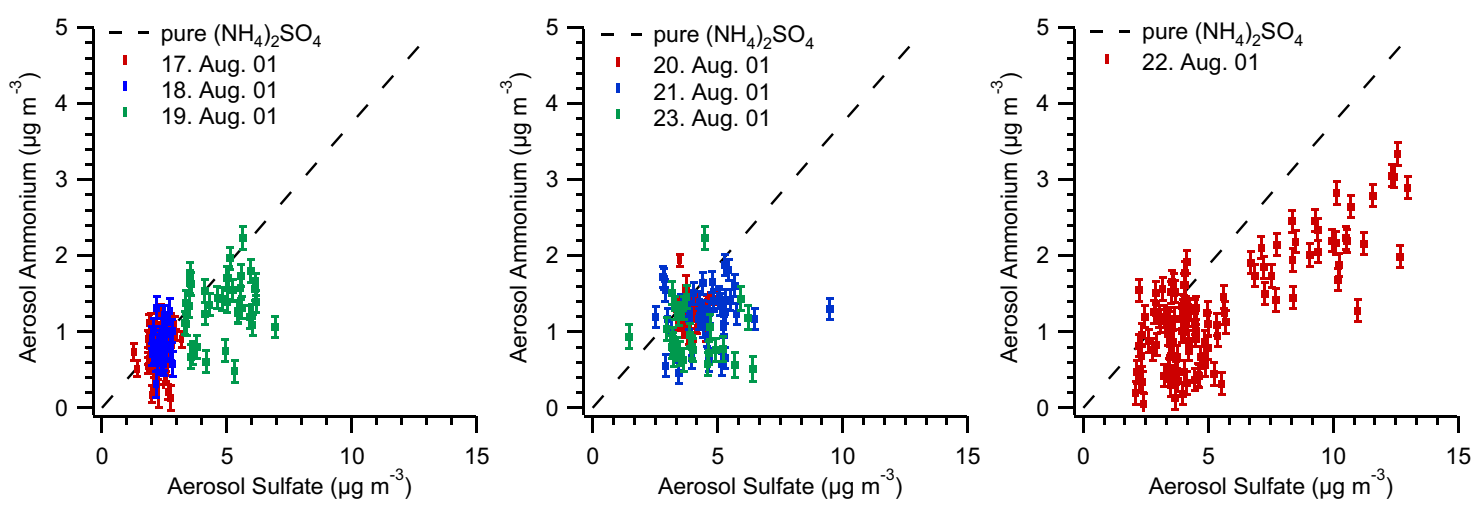

Fig. 5. Correlations between sulfate and ammonium for each measurement day. The dotted line represents the ratio for pure ammonium sulfate.

with low $\left(\mathrm{NH}_{4}\right)_{2} \mathrm{SO}_{4}$ concentrations $(17,18$, and 20 August), it appears that all sulfate can be neutralized by ammonium. On days with higher sulfate concentrations, there is excess sulfate (22 August, and to a lesser degree also 19, 21, and 23 August) which means that the aerosol is acidified and, as mentioned above, no ammonium nitrate can be formed.

Backward trajectories have been calculated with HYSPLIT4 (Draxler and Hess, 1997) using FNL data (Stunder, 1997). Figure 6 shows the 6-day backward trajectories for the time span of the AMS measurements (17-23 August 2001). The air masses sampled at Finokalia arrived from the North and have travelled over the Aegean Sea for a time span ranging between $12 \mathrm{~h}$ and 3 days, but have crossed a part of Greece and Turkey, and also the Black Sea. If the aerosol originates from anthropogenic emissions it must have spent a considerable time in the atmosphere and may have become processed by photochemistry. The vertical history of the air parcels (lower panel) indicates that the air masses on 21 and 22 August originate from close to the ground, while on the other days, the arriving air masses have descended from higher above. Most likely the high sulfate content mea- sured on 21 and 22 August is due to emissions from fossil fuel burning north of the Black Sea.

\subsection{Size distributions}

The aerosol size distributions on selected days, measured with various instruments, are shown in Fig. 7. During a flyby of the Israeli research aircraft "King Air" on 9 August 2001, a comparison of the ground based instruments (two OPCs inside the MPI/FZJ container and the diffusion particle sizer on the hilltop) and two aircraft-based instruments (one PCASP and one FSSP-100) was performed (top right panel in Fig. 7). This comparison yielded good agreement between the instruments. Apparently no major features in the size distribution structure between 200 and $270 \mathrm{~nm}$ were missed by the gap between the DPS and OPC size ranges. During the whole measurement period, the maximum of the aerosol number density (about $10^{4} \mathrm{~cm}^{-3}$ ) was observed in the accumulation mode between 100 and $200 \mathrm{~nm}$. Only few particles $\left(<100 \mathrm{~cm}^{-3}\right)$ were detected below $10 \mathrm{~nm}$, from which we conclude that no nucleation took place. Only on 
20 August and 21 August 2001, the number density below $10 \mathrm{~nm}$ reaches higher values of about $1000 \mathrm{~cm}^{-3}$. On these days, the air masses have spent more time over the Greek continent than over the Aegean Sea. (The corresponding trajectories to the measurement days in Fig. 7 are displayed in Fig. 8.)

The coarse mode extends up to about $10 \mu \mathrm{m}$. The upper detection limit of the ground based OPCs was $9 \mu \mathrm{m}$, and that of the FSSP-100 is $16 \mu \mathrm{m}$.

Figure 9 gives the mass size distribution of sulfate, measured with the AMS, averaged over the whole measurement period (17-23 August 2001). The calculated inlet transmission function is also given (Jayne et al., 2000). The sulfate size distribution has its peak at a modal diameter of ca. $550 \mathrm{~nm}$, and the upper side of the distribution falls into a region where the transmission is below $100 \%$. However, the calculated transmission function is regarded to be too uncertain to use it to correct the measured data. The sulfate size distribution can be approximated with a lognormal fit ( $\left.D_{0}=526 \mathrm{~nm}, \sigma=0.47\right)$ which is also shown.

Figure 10 shows the comparison between volume size distributions measured with the DPS, the OPC and the total mass size distribution measured with the AMS obtained on two days, 20 August 2001 (10:36-16:36 local time) and 21 August 2001 (11:45-17:45 local time). All 3 data sets have only been measured simultaneously on these days. The diffusion particle sizer measures the diffusive diameter, which is equal to the volume equivalent diameter if the particles are spherical. The optical particle counter is calibrated using the refractive index of PSL particles (1.59). Since the refractive index of the measured particles is not known and calculations of new size calibration functions for the geometry of the PALAS OPC are under way but are not available yet, we did not apply a correction to the size distribution measured with the OPC. We fitted a three-modal lognormal distribution to both the DPS and OPC data sets. These fits indicate an accumulation mode with a modal diameter of about $100 \mathrm{~nm}$ and a coarse mode with a modal diameter of $10 \mu \mathrm{m}$ on 20 August and $6.5 \mu \mathrm{m}$ on 21 August, respectively. The third mode between the accumulation and coarse mode is smaller and play only a minor role. On 20 August the volume concentration of the accumulation mode is larger almost by a factor of three than on 21 August.

The size distributions measured by the AMS have been recalculated to volume equivalent diameter. The relation between the volume equivalent diameter $D_{v}$ and the aerodynamic diameter $D_{a}$ in the continuum regime is (McMurry et al., 2002; Hinds, 1999):

$D_{a}=D_{v} \sqrt{\frac{\rho_{p}}{\rho_{0}} \frac{1}{\chi} \frac{C_{c}\left(D_{v}\right)}{C_{c}\left(D_{a}\right)}}$,

where $\rho_{p}$ is the density of the particle, $\rho_{0}$ the density of water $\left(1 \mathrm{~g} \mathrm{~cm}^{-3}\right), \chi$ is the dynamic shape factor, and $C_{c}(D)$ is
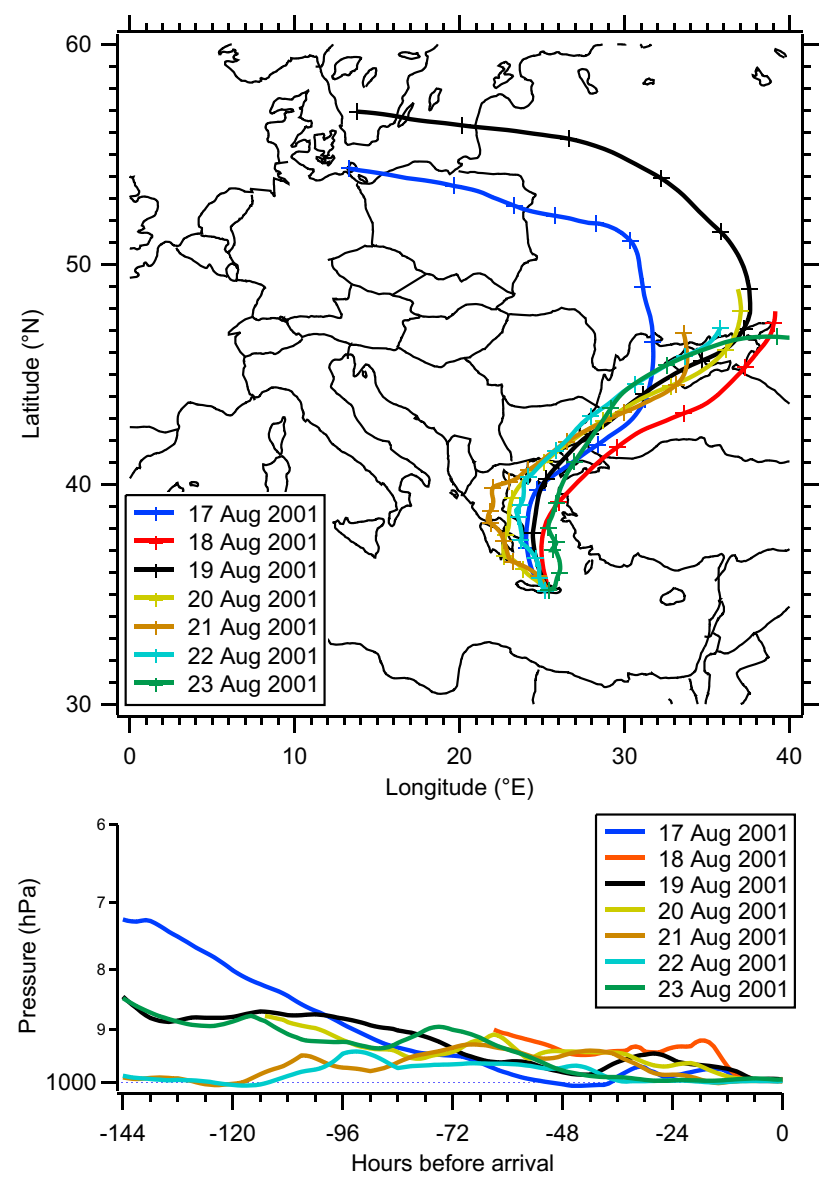

Fig. 6. 6-day backward trajectories for the time span between 17 and 23 August 2001, calculated with HYSPLIT using the FNL dataset. Ending point is Finokalia at 12:00. Upper panel: Horizontal history (crosses indicate $12 \mathrm{~h}$ traveling time), lower panel: vertical history.

the Cunningham slip correction. In the AMS inlet, the acceleration of the particles occurs in the free molecular regime. Stokes' law, which is valid only in the continuum regime, can be extended by the Cunningham correction into the free molecular regime (Allan and Raabe, 1982), where $C_{c}(D)$ becomes proportional to the inverse of the particle diameter $D$. Thus, the so-called "vacuum-aerodynamic diameter" $D_{v a}$ was introduced (Jimenez et al., 2003b):

$D_{v a}=D_{v} \frac{\rho_{p}}{\rho_{0}} \frac{1}{\chi}$.

Defining an effective density

$\rho_{e f f}=\frac{\rho_{p}}{\chi}$,

which includes the dynamic shape factor, we can match the AMS distribution to the accumulation mode measured with the two other instruments. We applied an effective particle density of $3.2 \mathrm{~g} \mathrm{~cm}^{-3}$ on 20 August and $2.4 \mathrm{~g} \mathrm{~cm}^{-3}$ on 21 

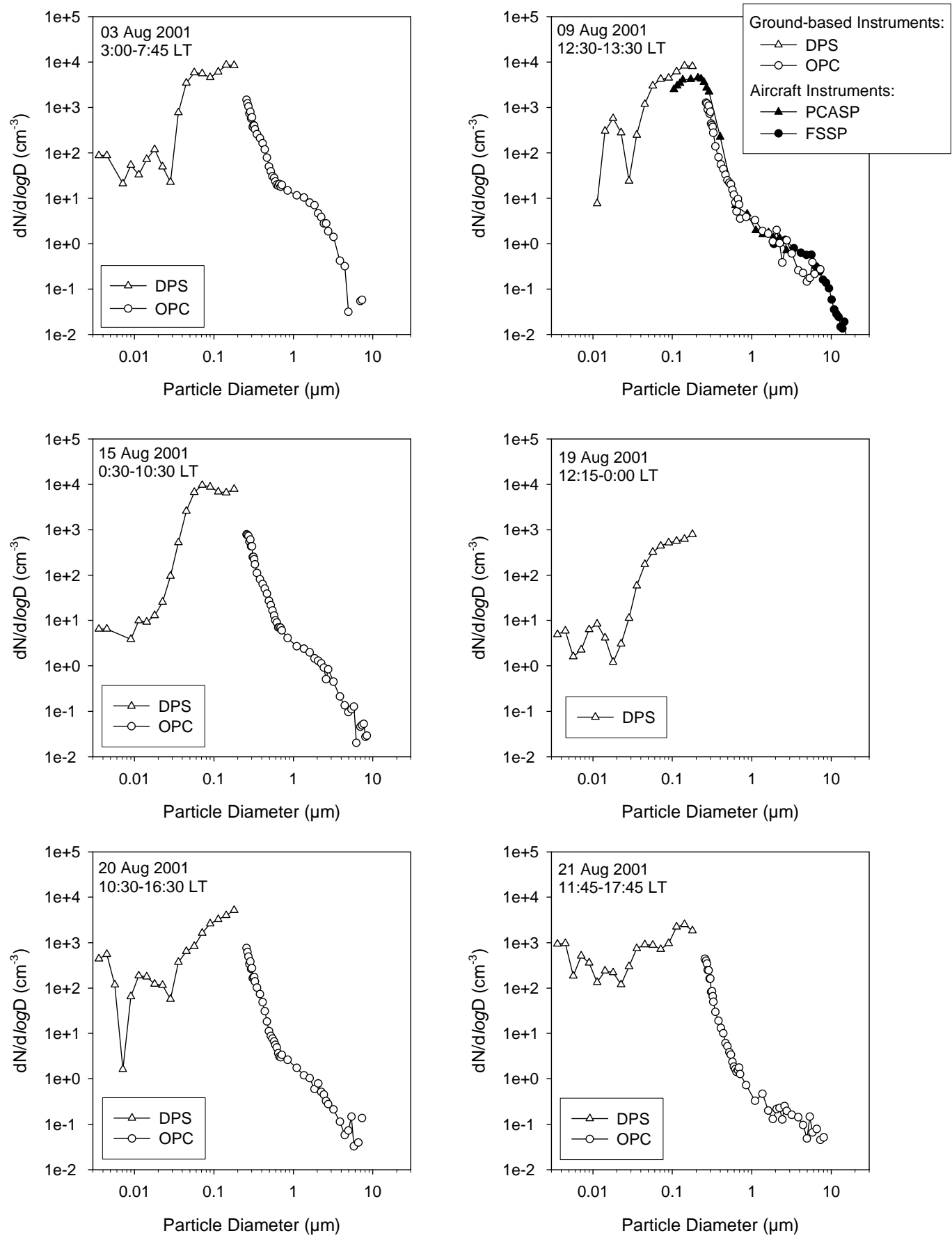

Fig. 7. Number size distributions measured with the Diffusion Particle Sizer (DPS, TSI-3040) and the Optical Particle Counter (OPC, PALAS PCS2010), during selected days of the campaign. On 9 August 2001, a comparison with two aircraft based instruments (PCASP, FSSP) during a fly-by of the Israeli King Air research aircraft was performed (top right panel). LT: Local time

August. This effective density refers to the whole aerosol particle, including the refractive and non-refractive material and can therefore be larger than the density of non-refractive aerosol compounds analyzed by the AMS. The broader shape of the mass distribution compared to the volume distribution may be due to a density distribution of the aerosol ensemble. The difference in the volume concentration of the accumulation mode between the two days suggest that different air masses and aerosol types were sampled on the two days. Also, the relative humidity on 20 August was $68 \%$ while it 

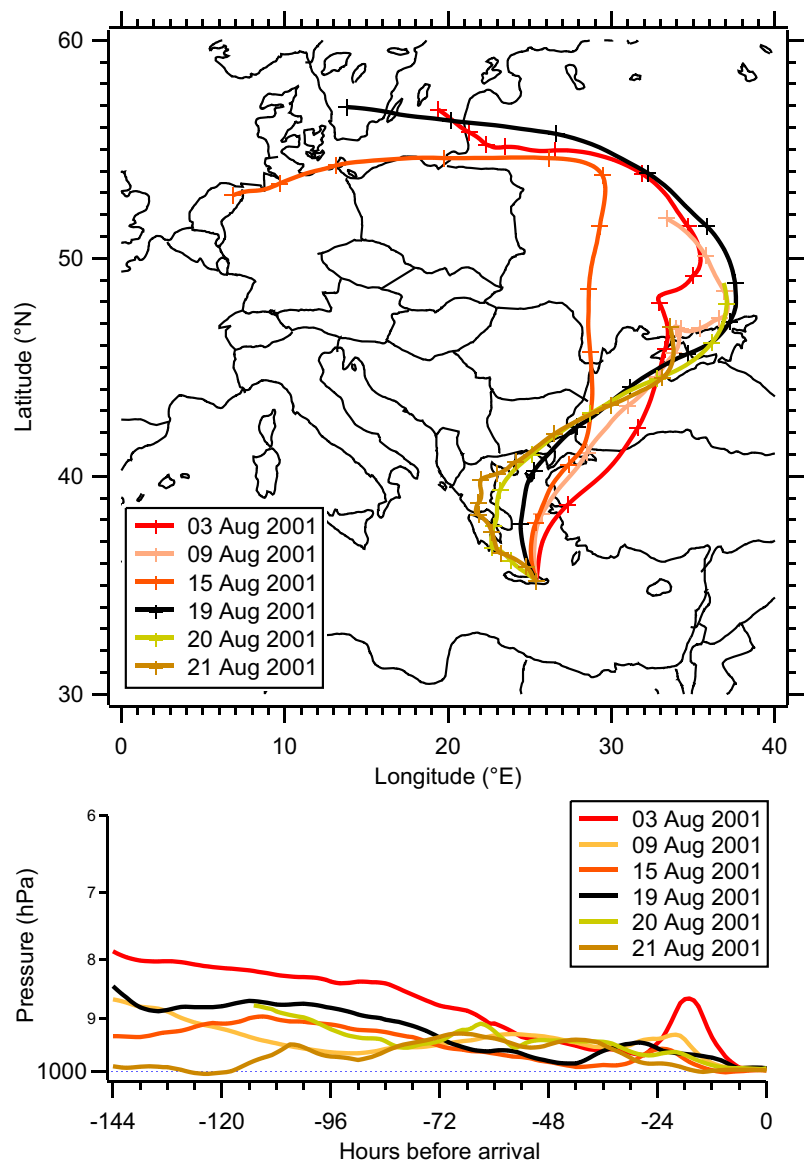

Fig. 8. 6-day backward trajectories corresponding to the measurements displayed in Fig. 7.

was only $32 \%$ on 21 August. Since the mass of sulfate and ammonium that are found in the accumulation mode is almost the same on the two days, the remaining particles on 20 August must have been composed of other material, e.g. organic or refractory material.

Figure 11 shows the comparison of the chemically speciated size distributions of the AMS with the results obtained with the MOUDI. The averaging time of the AMS data have been chosen to match the MOUDI time resolution (17-20 August, 20-23 August). Note that the MOUDI measured continuously and the AMS only during daytime. A bimodal lognormal fit was applied to the MOUDI results in order to facilitate the comparison of the accumulation mode with the AMS data. The size distribution measured by the AMS has been transformed to aerodynamic diameter (as measured by the MOUDI) using Eqs. (2) and (3) with the approximation for the Cunningham slip correction for the transition regime as given by Jimenez et al. (2003b):

$C_{c} \approx 1+\phi \frac{2 \lambda}{D}$

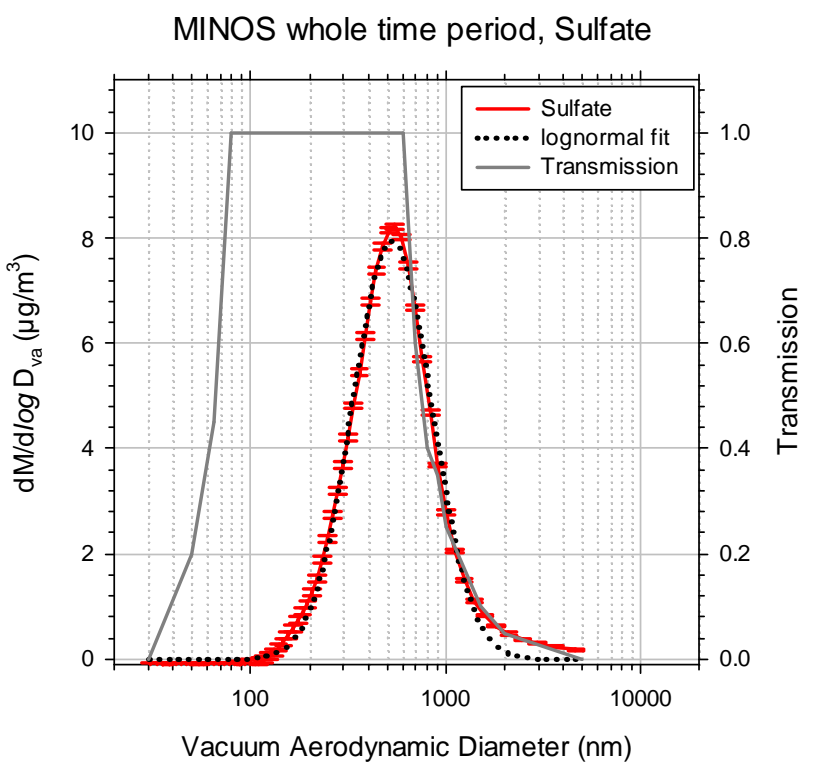

Fig. 9. Size distribution of sulfate containing particles measured with the AMS (red line), averaged over the whole operation period. The sulfate mass distribution can be approximated with a lognormal distribution (black line). Also shown is the calculated transmission function of the aerodynamic lens.

where $\phi=1.549$ and $\lambda$ is the mean free path which is ca. $66 \mathrm{~nm}$ at standard conditions $\left(T=20^{\circ} \mathrm{C}\right.$ and $\left.p=1013 \mathrm{hPa}\right)$. The result for the aerodynamic diameter $D_{a}$ is:

$D_{a}=\sqrt{\frac{\rho_{0}}{\rho_{p}} \chi} D_{v a} K$

with

$K=-\frac{\phi \lambda}{\sqrt{\frac{\rho_{0}}{\rho_{p}} \chi} D_{v a}}+\sqrt{1+\frac{\phi^{2} \lambda^{2}+2 \phi \lambda D_{v a}}{\frac{\rho_{0}}{\rho_{p}} \chi D_{v a}^{2}}}$,

Defining the effective density as above Eq. (4), we can match the size distributions by using values for $\rho_{\text {eff }}$ of 1.2 for the time period 17-20 August and 1.6 for the time period 20-23 August. This is contradictory to the comparison of the AMS size distributions with the DPS and the OPC (Fig. 9). A reason for this finding can not given at the present state of knowledge. The influence of the refractive index on the size distributions measured with the OPC is not expected to be large enough to have significant influence on the size distributions in Figs. 7 and 9. Between 17 and 20 August, the sulfate measured by the AMS amounts to $83 \%$ of the sulfate measured by the MOUDI, and the AMS ammonium amounts to $91 \%$ of the MOUDI ammonium, while between 20 and 23 August, these ratios were $80 \%$ (sulfate) and $71 \%$ (ammonium). These values refer to particles with aerodynamic diameters smaller than $1.5 \mu \mathrm{m}$. This underestimation by the AMS may be explained by the decreasing transmission for 

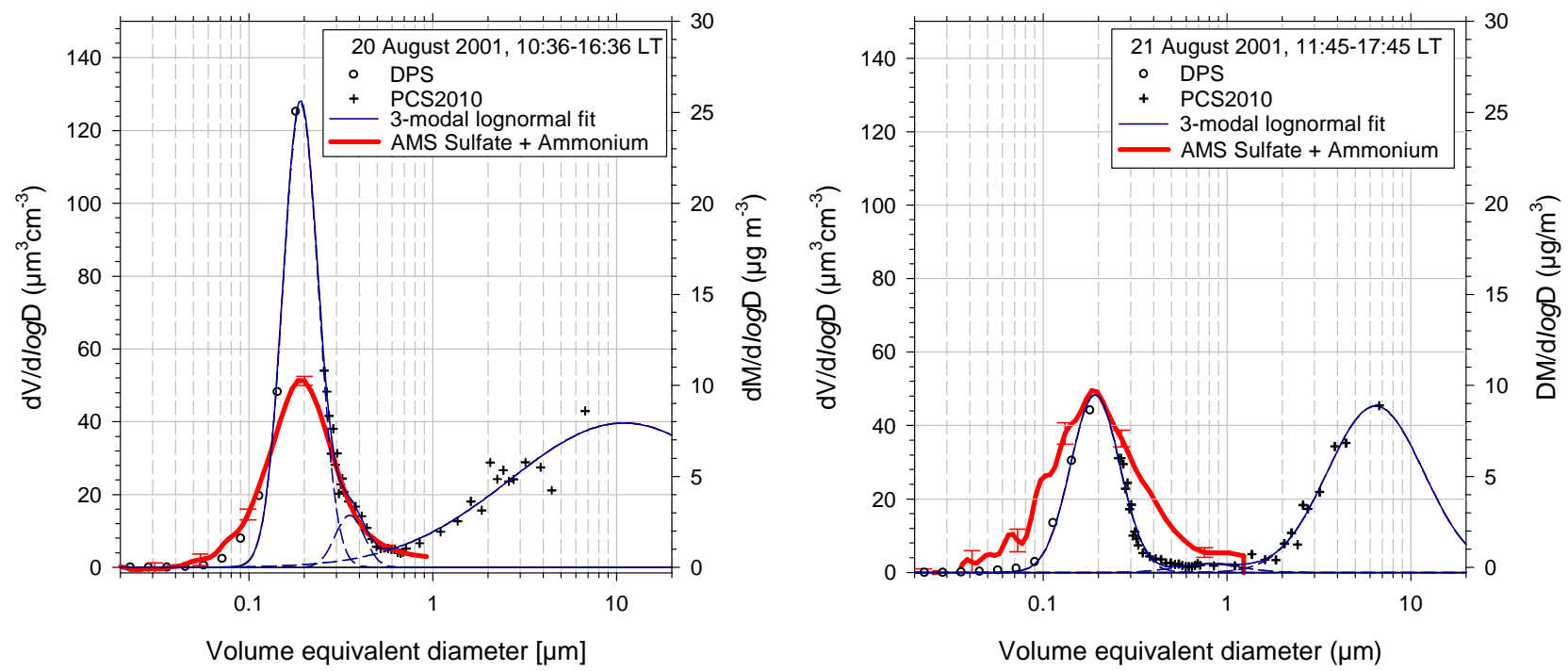

Fig. 10. Comparison between volume size distributions measured with the DPS, the OPC, and the sum of the sulfate and ammonium mass size distributions measured with the AMS. Left panel: 20 August 2001, right panel: 21 August 2001. Only for these days all 3 data sets have been measured simultaneously. The volume distributions measured by the DPS and the OPC can be reproduced by a 3-modal lognormal fit. To match the AMS distribution with the other data, an effective density of 3.2 and 2.4, respectively has been applied.

particle with diameters larger than $600 \mu \mathrm{m}$ (see Fig. 9). However, as mentioned above, since the transmission function is only calculated and not quantitatively measured yet, we do not intend to correct the data with this transmission function.

The accuracy of the filters used by the MOUDI is not high enough to detect nitrate in these small amounts, as indicated by the error bars. The AMS can not detect the nitrate contained in particles with diameters larger than about $1.5 \mu \mathrm{m}$, a fact that makes both methods complementary to each other. The single mass spectrometer SPLAT, which is able to detect particles larger than $1 \mu \mathrm{m}$, is not quantitative and will also benefit from an additional size selective, quantitative method.

\subsection{Ion series analysis of the organic compounds}

Although the "organics" fraction of the AMS can not be resolved into specific components, it is possible to retrieve information about certain groups of organic species, by means of the so-called ion series analysis, or $\Delta$-analysis (McLafferty and Turecek, 1993). For this technique it is assumed that the organic molecules consist of a functional group $\mathrm{R}$ with $\mathrm{CH}_{2}$ chains attached. Fragmentation is assumed to lead only to the strip-off of $\mathrm{CH}_{2}$ units. Hence, the mass peaks at which the fragments appear are a function of the functional group, and fragments separated by $m / z=14$ can be classified into one $\Delta$-group.

The $\Delta$ values are defined as $\Delta=$ peak mass $-14 n+1$, with $\mathrm{n}$ being the maximum possible number of Carbon atoms remaining on the functional group. The applicability of this technique to aerosol mass spectrometer data has been shown by Drewnick et al. (2003). Certain $\Delta$-groups could previ- ously be identified as signatures of certain types of organic particles, e.g. $\Delta=0,2$ : traffic related aerosol, $\Delta=3$ : oxygenated aerosol, $\Delta=-3 \ldots-7$ : aromatics (Drewnick et al., 2003). The present data have been analyzed by this technique in a day-by-day basis. The results are given in Fig. 12, where the relative contribution of each $\Delta$-group to the total organic fraction for each day is displayed. It can be clearly be seen that the $\Delta$-group 3 is the largest, but the $\Delta$-groups 0 and 2 play a significant role as well. Oxygenated organic aerosol compounds are thought to be formed either by photochemically processed precursor gases or directly by biomass burning. Sciare et al. (2003b) conclude that $2 / 3$ of the organic carbon in the aerosol originates from biomass burning. On the other hand, it can not be ruled out that a large fraction of the aerosol precursor gases originates from South-East Europe and has been photochemically processed during the travel over the Mediterranean Sea. It is very likely that both sources (pollution from Eastern Europe and biomass burning) contribute to the high aerosol number density measured during the campaign. The fact that the $\Delta$-groups 0 and 2 are also present suggests that these groups are not only an indicator for traffic, but also for industrial emissions in general.

The ratio of $\Delta$-group 3 to $\Delta$-group 2 is high on 18,20 , 21 and 23 August 2001, while it is lower on 17, 19, and 22 August 2001. The backward trajectories (Fig. 6) reveal that the air masses that arrived at Finokalia on 17, 19, and 23 August descended from higher altitudes, but this does not correspond completely to the days with a low $\Delta 3$ to $\Delta 2$ ratio. Another finding is that the air masses that arrived at Finokalia on 20 and 21 August 2001 have travelled a longer 
17. - 20. Aug. 2001
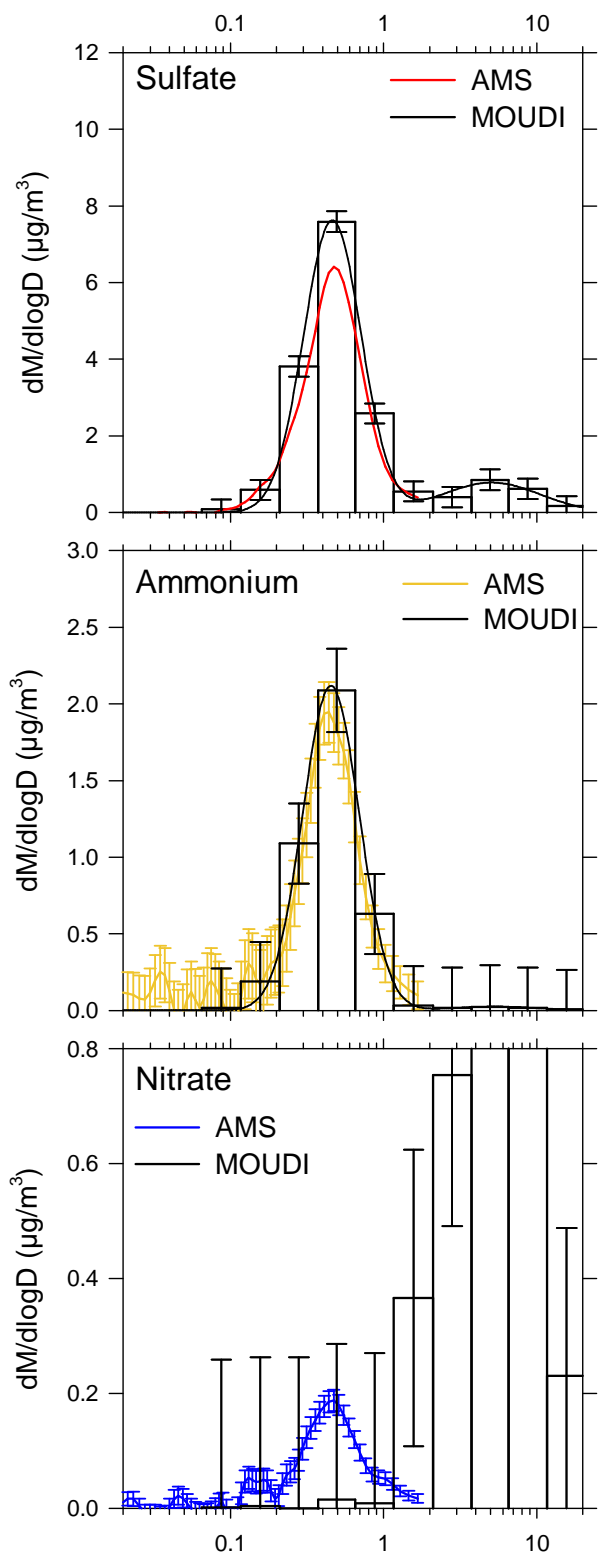

Aerodynamic diameter $(\mu \mathrm{m})$
20. - 23. Aug. 2001
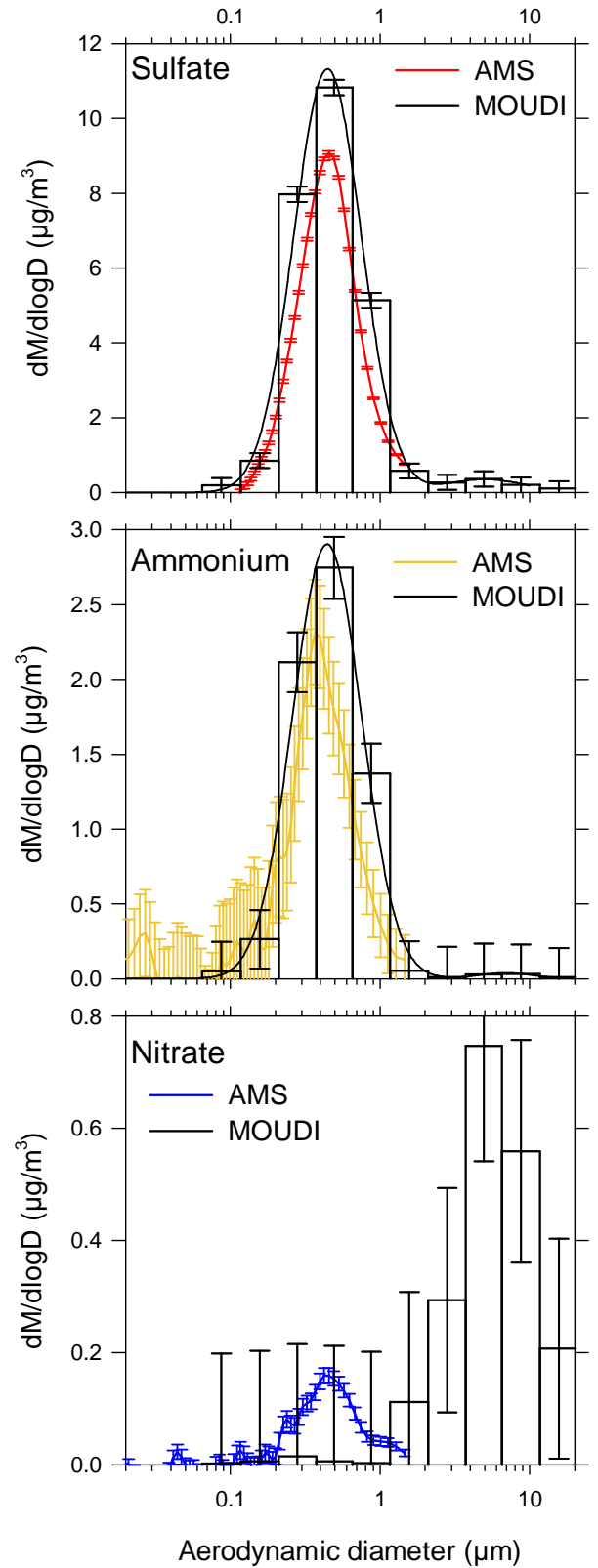

Fig. 11. Comparison between size distributions of individual chemical components of the aerosol particles between AMS and MOUDI. Left: Average 17-20 August 2001; right: average 20 August-23 August 2001. To match the AMS distribution with the MOUDI data, an effective density of 1.2 and 1.6, respectively, had to be applied.

distance over the Greek continent than over the Aegean Sea. As already mentioned in Sect. 3.2, these differences in the geographical origin is reflected by the size distribution of these two days (Fig. 7): The number concentration on the lower end of the distribution is higher on 20 and 21 August 2001 (between 100 and $1000 \mathrm{~cm}^{-3}$ ) while on the other days, there are only below $10-100 \mathrm{~cm}^{-3}$ in this size range. The ratio between $\Delta$-group 3 and 2 is larger $(1.68 \pm 0.15)$ on average on 20 and 21 August than the average on the other analyzed days $(1.31 \pm 0.12)$. If this finding is somehow related to the air mass history and the higher number density of small aerosol particles, can not be answered definitely. For comparison of the $\Delta$-analysis results with previous measurements, Drewnick et al. (2003) found a ratio between $\Delta$-group 3 and 2 of about 0.7 during a field study in New York City where it is not surprising that traffic related organics aerosol is dominating. 
(17 Aug 01 12:00 to 20:00)

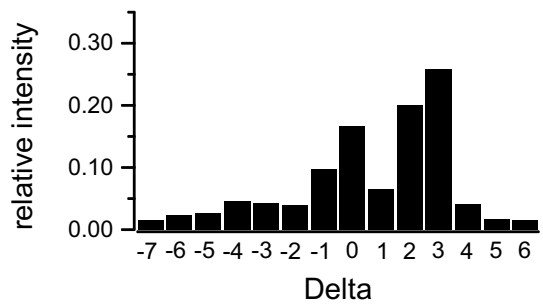

(19 Aug 01 15:00 to 20:45)

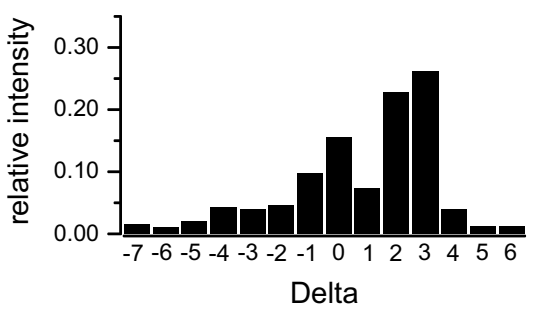

(21 Aug 01 12:44 to 18:59)

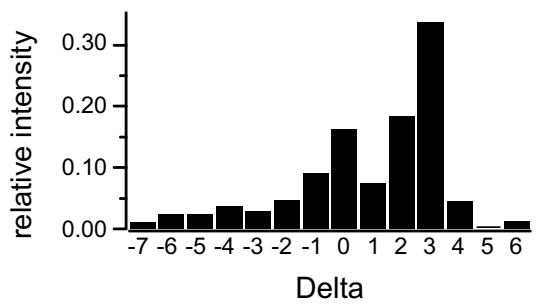

(23 Aug 01 12:18 to $14: 59$ )

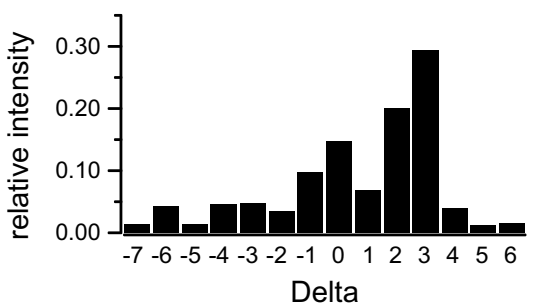

(18 Aug 01 14:10 to $21: 00$ )

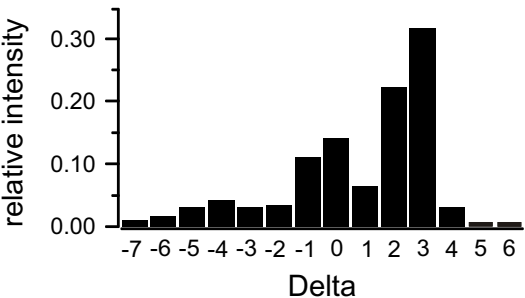

(20 Aug 01 10:45 to 18:14)

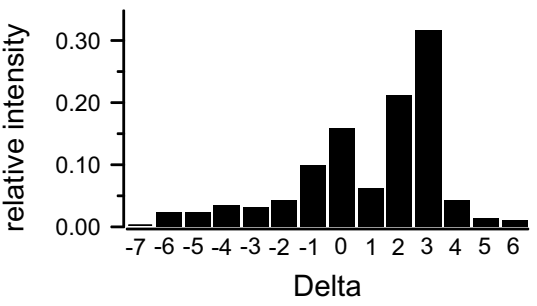

(22 Aug 01 11:40 to 22:11)

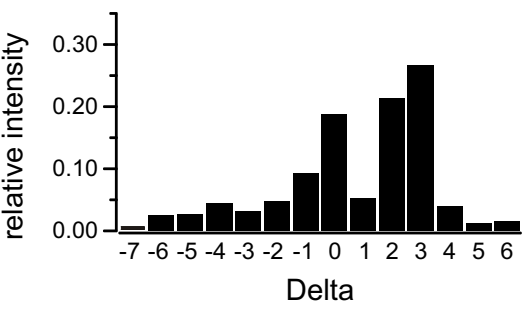

Fig. 12. Ion series analysis of the organics fraction measured with the AMS. The dominating $\Delta$-group is $\Delta=3$ for all days, supporting the conclusion that the aerosol particles contained oxygenated organics which are an indicator for biomass burning or aged aerosol.

\subsection{Comparison of mass concentrations}

Average mass concentrations of the individual components measured with the AMS, the MOUDI, and the IC analyses of the quartz filter samples are given in Table 2. For details of the MOUDI and filter analyses see Sciare et al. (2003b). The AMS and filter data have been averaged over the MOUDI sampling intervals: 17 August 2001, 16:45-20 August 2001, 9:30, and 20 August 2001, 11:15-23 August 2001, 13:15. Only fine mode data $(D<1.2 \mu \mathrm{m})$ were considered for the MOUDI and filter data. The AMS inlet transmission (see
Fig. 9) decreases from $100 \%$ at about $600 \mathrm{~nm}$ down to about $10 \%$ at $1.2 \mu \mathrm{m}$, which means that the AMS measures only the fine mode aerosol, but will underestimate slightly the fine mode mass. For the first sample time interval, the values for sulfate and ammonium agree within their error limits. For the second interval, the MOUDI yields markedly higher values for sulfate and ammonium (33\% and 32\% compared to the AMS, respectively). However, it has to be considered that the AMS was only operative during daytime and therefore the AMS data do not represent exactly the same averaging intervals as the MOUDI and filter data. The IC results from 
Table 2. Comparison of fine mode $(<1.2 \mu \mathrm{m})$ mass concentrations measured with different techniques: mass spectrometer, MOUDI and filter with GC analysis. The AMS data and the filter data have been averaged to match the MOUDI sample periods. Note that the MOUDI and filter analyses included more compounds than sulfate, nitrate, and ammonium, which are not shown in this table. For details of the MOUDI and filter results see Sciare et al. (2003b).

\begin{tabular}{lccc}
\hline Mass concentration $\left(\mu \mathrm{g} / \mathrm{m}^{3}\right)$ & AMS & MOUDI & Filters \\
\hline 17-20 August 2001 & & & \\
\hline Sulfate & $3.73 \pm 1.23$ & $3.61 \pm 0.11$ & $6.33 \pm 1.90$ \\
Ammonium & $1.12 \pm 0.25$ & $0.99 \pm 0.11$ & $2.10 \pm 0.65$ \\
Nitrate & $0.10 \pm 0.004$ & $0.008 \pm 0.11$ & $0.08 \pm 0.03$ \\
Organics (sum) & $1.32 \pm 0.16$ & - & $5.67 \pm 0.58$ \\
Total & $6.27 \pm 1.27$ & $12.45 \pm 0.11$ & $16.65 \pm 3.19$ \\
\hline 20-23 August 2001 & & & \\
\hline Sulfate & $4.63 \pm 0.57$ & $6.18 \pm 0.09$ & $7.95 \pm 2.83$ \\
Ammonium & $1.23 \pm 0.07$ & $1.62 \pm 0.09$ & $2.41 \pm 0.65$ \\
Nitrate & $0.08 \pm 0.01$ & $0.009 \pm 0.09$ & $0.09 \pm 0.06$ \\
Organics (sum) & $1.05 \pm 0.09$ & - & $5.32 \pm 0.26$ \\
Total & $6.99 \pm 0.58$ & $16.36 \pm 0.09$ & $18.83 \pm 3.72$ \\
\hline
\end{tabular}

the filters samples yield a markedly higher content of ammonium sulfate for both sampling intervals compared to both the AMS and the MOUDI. All three methods agree that the nitrate content was about $0.1 \mu \mathrm{g} / \mathrm{m}^{3}$. The sum of organics measured by the AMS and obtained from the filters differs markedly: The AMS yields only $20-25 \%$ of the filter results. We assumed that the organic aerosol was externally mixed with the sulfate aerosol and therefore used a collection efficiency of 1 (see Sect. 2.1.2 and Table 1). If the organic aerosol would also be sampled with an efficiency of 0.5 , the calculated organic mass concentrations have to be multiplied with a factor of 2 . However, if the organic aerosol and the ammonium sulfate aerosol were internally mixed, the collection efficiency would probably be higher than 0.5 since the particles will be less irregular shaped than pure ammonium sulfate crystals. Furthermore, it is conceivable that the ionization efficiency of individual organics in the AMS is not known well enough. As described in Allan et al. (2003a), the relative ionization efficiency of organic substances varies for different types of organics in a range of 0.5 to 0.7 .

Summarizing, the organic mass concentration measured by the AMS might have to be corrected by an unknown factor between 1 and 2. Still, a factor of 2 would lead only to an measured AMS organics fraction of 40-50\% compared to the filter results (Table 2).

It might be conceivable that the filters sample some fraction of the gas phase organic as well as particulate organic. Such artifacts due to the absorption of gas-phase organic compounds on the sample substrate were minimized by heating filters for $20 \mathrm{~min}$ at $60^{\circ} \mathrm{C}$ prior to the 2-step thermal/thermo-optical analysis. However, such artifacts do not impact significantly the determination of the light absorbing material of the aerosol (one of the major concerns of the
MINOS campaign). Very good agreement for black and total carbon concentrations was obtained between the quartz bulk filters and the DEKATI cascade impactor samples which have been collected throughout the campaign (Sciare et al., 2003c). The slope close to 1 found between the two sampling techniques - with all data points lying within a $10 \%$ errors in mass concentrations - suggests that sampling artifacts, which are not corrected by the pre-treatment at $60^{\circ} \mathrm{C}$, did not affect significantly the whole organic carbon mass concentration of the samples. Such conclusion reinforces the ability of the measurements to be used for the mass closure experiments of sub micron aerosols as performed by Sciare et al. (2003c) during the MINOS campaign.

Comparison of the total mass concentrations of the nonrefractory aerosol detected by the AMS and the total aerosol mass measured by the MOUDI and the filters yields ratios between 0.37 and 0.5 . This ratio of non-refractory mass and total aerosol mass lower than that observed by Drewnick et al. (2003) who measured a fraction of about $64 \%$ detected with the AMS during a campaign in New York City. This undetected mass does most likely consist of refractory material, e.g. mineral dust or black carbon, which does not evaporate at the heater temperature. However, Sciare et al. (2003b) found that black carbon contributed only $22 \%$ to the total carbon (12-23 August 2001), while it would require about $68 \%$ to close the mass balance in Table 2. Other refractory material, like mineral dust and fly ash, contributed only to about $10 \%$ of the fine aerosol mass (Lelieveld et al., 2002). Thus, the large difference between the mass measured and the filter sampled remains unresolved. 

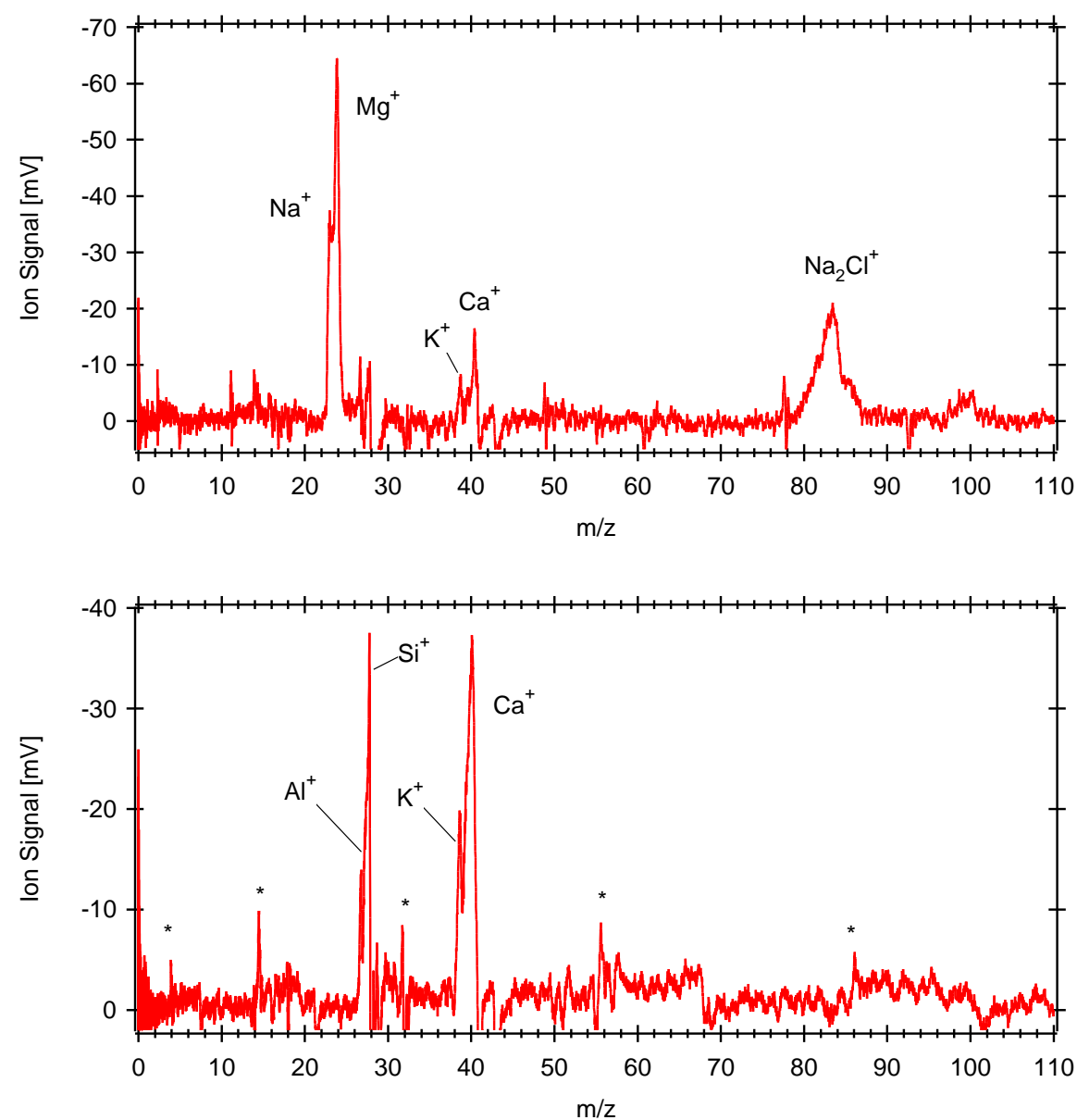

Fig. 13. Two mass spectra obtained with the SPLAT instrument on 13 August 2001. Upper panel: sea salt particle $(\mathrm{NaCl}), D_{a e r o}=2.9 \mu \mathrm{m}$; lower panel: mineral dust particle, $D_{\text {aero }}=2.1 \mu \mathrm{m}$.

\subsection{Single particle analyses of the large particle fraction}

The single particle mass spectrometer (SPLAT) was operated during the MINOS campaign in a preliminary state of development. A detailed discussion of the instrumental characteristics, data extraction and first results is carried out in Wollny (2002). During almost $10 \mathrm{~h}$ operation time on several days 1062 single particles were detected. A small fraction of these particles (size range between 1 and $5 \mu \mathrm{m}$ ) was hit by the ionization laser. Mass spectra of positive ions have been obtained for 57 single particles. The detector for the negative ions could not be operated successfully due to a high voltage power supply failure. Most of the particles (51) contained elemental ions from mineral aerosol in the mass spectra, like $\mathrm{Ca}^{+}, \mathrm{Al}^{+}, \mathrm{Fe}^{+}, \mathrm{Ni}^{+}, \mathrm{Co}^{+}$, and partly also $\mathrm{Na}^{+}$and $\mathrm{Mg}^{+} . \mathrm{A}$ typical mass spectrum from this "mineral aerosol" group is displayed in the upper panel of Fig. 13. Only two particles have led to spectra that could be interpreted as sea salt particles. One of them is shown in the lower panel of Fig. 13. Kievit (1995) has shown in laboratory studies the presence of $\mathrm{Na}_{2} \mathrm{Cl}^{+}$-cluster in mass spectra of laser ablation of $\mathrm{NaCl}-$ particles. The remaining mass spectra could not be clearly identified. Possible components include ammonium sulfate or soot. The SPLAT measurements indicate that during the operation time most of the analyzed particles in the coarse mode were mineral aerosols. This conclusion agrees with the results from the MOUDI and the IC analysis of the filter samples, which yielded $46 \%$ dust and $25 \%$ sea salt/nitrate (MOUDI), and $42 \%$ dust and $36 \%$ sea salt/nitrate (filters). These dust particles have been found to be not of local but mainly regional origin (Sciare et al., 2003c).

\section{Summary and conclusions}

We have measured microphysical and chemical aerosol properties with various analytical methods: mass spectrometers, filter samples, optical particle counters, nucleation particle counters, and a diffusion sizer during a field study in the Eastern Mediterranean. The Aerosol Mass Spectrometer (AMS) found the non-refractory fine mode aerosol (with diameters 
smaller than about $1 \mu \mathrm{m}$ ) to be composed of 77-84\% ammonium sulfate and between 15 and $21 \%$ organic material. The nitrate content was below $2 \%$. The non-refractory aerosol components made up to between 37 and $50 \%$ of the total aerosol mass in the fine mode.

From the composition of the submicron aerosol it can be concluded, that the aerosol (or, more precisely, its precursor gases) is mainly of anthropogenic origin. The high amount of ammonium sulfate suggests fossil fuel burning in SouthEastern Europe as the major sources. This finding is in excellent agreement with previous studies (Ganor et al., 2000; Sciare et al., 2003a; Kouvrakis and Mihalopoulos, 2002), who also found that anthropogenic sources are responsible for the high amount of sulfate in the Eastern Mediterranean in summer. The high contribution of oxygenated hydrocarbons in the organic fraction of the aerosol (the $\Delta-3$ group in the mass spectra) may indicate that part of the aerosol originates from biomass burning, but can also be an indicator for aerosol formed from photochemically aged precursor gases. The latter is not unlikely, because the aerosol must have spent between 12 and $60 \mathrm{~h}$ in the atmosphere before being analyzed at the Finokalia station. Considering the high solar intensity in the summer Mediterranean, photochemical conversion must have occurred if the emissions originate from the South-Eastern European continent and were transported to Crete. The absence of high number concentrations in the ultrafine particle mode (below $100 \mathrm{~nm}$ ) during most of the time also indicates that the conversion of the precursor gases into the aerosol phase has already occurred and that no fresh nucleation took place shortly before the measurements.

Comparison of the data from the new mass spectrometer technique (AMS) with the results of the MOUDI fine mode $(<1.2 \mu \mathrm{m})$ yielded fairly good agreement of both absolute mass concentrations and size distributions for sulfate and ammonium. The data measured with the 12-hour filter samples for the fine mode $(<1.2 \mu \mathrm{m})$ yielded a higher for ammonium sulfate mass concentration than the AMS and the MOUDI data. All three methods agree with the finding that the nitrate mass concentration was in the order of $0.1 \mu \mathrm{g} / \mathrm{m}^{3}$.

The single particle instrument (SPLAT) produced results that qualitatively agree with the filter and MOUDI results for the coarse mode: This mode was mainly composed of sea salt and mineral dust. The number of single particle spectra obtained during this campaign was very small, which was mostly due to problems with the inlet system and the optical detection of the particles.

The combination of established (MOUDI, filter samples, OPCs, CPCs) and new instrumental techniques (AMS, SPLAT) as it was used during the MINOS project offers the possibility to gain new insight into the chemical composition and size distribution of submicron and supermicron aerosols. The two mass spectrometric techniques are complementary in their size range and in their ability to measure quantitatively bulk aerosol and qualitatively single particles, but both offer a high time resolution compared to other size-selective and quantitative methods that rely on filter samples. It is encouraged to use a combination of instruments as it was used during MINOS for future aerosol studies.

Acknowledgements. We would like to thank T. Böttger for technical support during the campaign, M. de Reus and P. Petsalakis for the organization of the MINOS campaign, J. D. Allan and all contributors for the AMS evaluation software, F. Drewnick for discussion about the ion series analysis, and C. Schiller for the use of the FZJ/ICG-1 measurement container.

\section{References}

Alfarra, M. R., Coe, H., Allan, J. D., Bower, K. N, Boudries, H., Canagaratna, M. R., Jimenez, J. L., Jayne, J. T., Garforth, A., Li, S.-M., and Worsnop, D. R.: Characterization of urban and regional organics aerosols in the Lower Fraser Valley using two Aerodyne aerosol mass spectrometers, submitted to Atm. Env., 2003.

Allan, J. D., Jimenez, J. L., Coe, H., Bower, K. N., Williams, P. I., and Worsnop, D. R.: Quantitative Sampling Using an Aerodyne Aerosol Mass Spectrometer, Part 1: Techniques of Data Interpretation and Error Analysis, J. Geophys. Res., 108, 4090, doi:10.1029/2002JD002358, 2003a.

Allan, J. D., Coe, H., Bower, K. N., Alfarra, M. R., Delia, A. E., Jimenez, J. L., Middlebrook, A. M., Drewnick, F., Onasch, T. B., Canagaratna, M. R., Jayne, J. T., and Worsnop, D. R.: Technical note: Extraction of chemically resolved mass spectra from Aerodyna aerosol mass spectrometer data, submitted to J. Aerosol Sci., 2003b.

Bläsner, M.: Entwicklung eines bipolaren flugzeuggetragenen Aerosolmassenspektrometers, Ph. D.thesis (in German), University Bonn, Germany, 2001.

Draxler, R. R. and Hess, G. D.: Description of the HYSPLIT_4 modeling system, NOAA Tech. Memo., ERL ARL-224, Matl. Oceanic and Atmos. Admin. Washington D.C., 1997.

Drewnick, F., Schwab, J. J., Jayne, J. T., Canagaratna, M., Worsnop, D. R., and Demerjian, K. L.: Measurement of Ambient Aerosol Composition during the PMTACS-NY 2001 using an Aerosol Mass Spectrometer, Part I: Mass Concentrations, Aer. Sci. Techn., in press, 2003.

Ganor, E., Foner, H. A., Bingemer, H. G., Udisti, R., and Setter, I.: Biogenic sulfate generation in the Mediterranean Sea and its contribution to the sulfate anomaly in the aerosol over Israesl and the Eastern Mediterranean, Atm. Env., 34, 3453-3462, 2000.

Gross, D. S., Gälli, M. E., Silva, P. S., und Prather, K. A.: Relative sensitivity factors for alkali metal and ammonium cations in single-particle aerosol time-of-flight mass spectra, Anal. Chem., $72,416-422,2000$.

Hinds, W. C.: Aerosol Technology: Properties, Behavior, and Measurement of Airborne Particles, 2. Edition, John Wiley \& Sons, Inc., New York, 1999.

Hinz, K.-P., Kaufmann, R., und Spengler, B.: Simultaneous detection of positive and negative ions from single airborne particles by real-time laser mass spectrometry, Aerosol Science and Technology, 24, 233-242, 1996.

Hogrefe, O., Drewnick, F., Lala, G. G., Schwab, J. J., and Demerjian, K. L.: Development, Operation and Applications of an 
Aerosol Generation, Calibration and Research Facility, Aer. Sci. Techn., in press, 2003.

Jayne, J. T., Leard, D. C., Zhang, X., Davidovits, P., Smith, K. A., Kolb, C. E., and Worsnop, D. R.: Development of an aerosol mass spectrometer for size and composition analysis of submicron particles, Aerosol Sci. Technol., 33, 49-70, 2000.

Jimenez, J. L., Jayne, J. T., Shi, Q., Kolb, C. E., Worsnop, D. R., Yourshaw, I., Seinfeld, J. H., Flagan, R. C., Zhang, X., Smith, K. A., Morris, J., and Davidovits, P.: Ambient Aerosol Sampling with an Aerosol Mass Spectrometer. J. Geophys. Res., 108, 8425, doi:10.1029/2001JD001213, 2003a.

Jimenez, J. L., Bahreini, R., Cocker, D. R., Zhuang, H., Varutbangkul, V., Flagan, R. C., Seinfeld, J. H., O’Dowd, C. D., and Hoffmann, Th.: New particle formation from photooxidation of diiodomethane $\left(\mathrm{CH}_{2} \mathrm{I}_{2}\right)$ J. Geophys Res., 108, 4318, doi:10.1029/2002JD002452, 2003b.

Kouvrakis, G., Tsigaridis, K., Kanakidou, M., and Mihalopoulos, N.: Temporal variations of surface regional background ozone over Crete Island in the Southeast Mediterranean, J. Geophys. Res., 105, 4399-4407, 2000.

Kouvrakis, G. and Mihalopoulos, N.: Seasonal variation of dimethylsulfide in the gas phase and of methanesulfonate and non-sea-salt sulfate in the aerosols phase in the Eastern Mediterranean atmosphere, Atm. Env., 36, 929-938, 2002.

Kievit, O.: Development of a laser mass spectrometer for aerosols, Ph.D. thesis, Technical University Delft, The Netherlands, 1995.

Lelieveld, J., Berresheim, H, Borrmann, S., et al.: , Global air pollution crossroads over the Mediterranean, Science, 298, 794-799, 2002.

Marijnissen, J. B., Scarlett, B., and Verheijen, P.: Proposed online aerosol analysis combining size determination, laser-induced fragmentation and time-of-flight mass spectroscopy, J. Aerosol Sci., 19, 1307-1310, 1988.

Mihalopoulos, N., Stephanou, E., Kanakidou, M., Pilitsidis, S., and Bousquet, P.: Tropospheric aerosol ionic composition in the Eastern Mediterranean region, Tellus 49B, 314-326, 1997.
McLafferty, F. W. and Tureck, F.: Interpretation of mass spectra, University Science Books, Sausalito, Ca, 1993.

Markowicz, K. M., Flatau, P. J., Ramana, M. V., Crutzen, P. J., and Ramanathan, V.: Absorbing mediterranean aerosols lead to a large reduction in the solar radiation at the surface, Geophys. Res. Lett., 29(20), 1968, doi:10.1029/2002GL015767, 2002.

Noble, C. A. and Prather, K. A.: Real-time single particle mass spectrometry: A historical review of a quarter century of the chemical analysis of aerosols, Mass Spectr. Rev., 19, 248-274, 2000.

Prather, K. A., Nordmeyer, T., and Salt, K.: Real-time characterization of individual aerosol particles using time-of-flight mass spectrometry, Analytical Chemistry, 66, 1403-1407, 1994.

Sciare, J., Bardouki, H., Moulin, C., and Mihalopoulos, N.: Aerosol sources and their contribution to the chemical composition of aerosols in the Eastern Mediterranean Sea during summertime, Atmos. Chem. Phys., 3, 291-302, 2003 a.

Sciare, J., H. Cachier, K. Oikonomou, P. Ausset, R. Sarda-Estève, and N. Mihalopoulos, Characterization of carbonaceous aerosols during the MINOS campaign in Crete, July-August 2001: a multi-analytical approach, Atmos. Chem. Phys., 3, 1743-1757, 2003b.

Sciare, J., Oikonomou, K., Maenhaut, W., Sarda-Estève, R., Cachier, H., and Mihalopoulos, N.: Chemical mass closure of size-resolved aerosols during the MINOS campaign in Crete Isl., to be submitted to Atmos. Chem. Phys. Discuss., 2003c.

Stunder, B. J. B.: NCEP Model Output - FNL ARCHIVE DATA, TD-6141, National Climatic Data Center (NCDC), http://www. arl.noaa.gov/ss/transport/archives.html, 1997.

Wollny, A. G.: Entwicklung eines bipolaren Flugzeitmassenspektrometers zur Analyse der chemischen Zusammensetzung von individuellen Aerosolpartikeln, $\mathrm{Ph}$. D. thesis (in German), University Bonn, Germany, 2002.

Zhang, X., Smith, K. A., Worsnop, O. R., Jimenez, J., Jayne, J. T., and Kolb, Ch. E.: A Numerical Characterization of Particle Beam Collimation by an Aerodynamic Lens-Nozzle System: Part I. An Individual Lens or Nozzle, Aerosol Sci. Techn. 36, 617-631, 2002. 